\title{
Os argumentos quase lógicos e os lugares da argumentação no gênero propaganda oral radiofônica
}

\author{
The almost logical arguments and places of argumentation in the genre of oral \\ radiophonic advertising
}

\author{
Max Silva da ROCHA* \\ Maria Francisca Oliveira SANTOS**
}

\begin{abstract}
RESUMO: Por meio dos estudos retóricos, é possível entender o emprego das técnicas argumentativas utilizadas por oradores para tentar convencer e persuadir determinado auditório social. Diante desse entendimento, este trabalho tem como principal objetivo analisar os argumentos quase lógicos e os lugares da argumentação presentes no gênero propaganda oral radiofônica veiculado na rádio alagoana. Desse modo, o trabalho entende a Retórica como um mecanismo discursivo capaz de verificar como se dá a persuasão nos mais diversos discursos. A partir desse posicionamento, este estudo filia-se, metodologicamente, à perspectiva qualitativa, pois dá ênfase ao processo dos dados e não ao produto final. O olhar descritivo-interpretativista da abordagem qualitativa permite ao pesquisador observar os dados processualmente. Por isso, embasa-se nos referenciais teóricos de Abreu (2009), Aristóteles (2011), Ferreira (2015), Meyer (2007), Perelman e Olbrechts-Tyteca (2014), Santos (2011; 2018), entre outros. O foco da análise é o espaço radiofônico,

ABSTRACT: Through rhetorical studies, it is possible to understand the use of argumentative techniques used by speakers to try to convince and persuade a certain social audience. In view of this understanding, this work has as main objective to analyze the almost logical arguments and the places of the argumentation present in the genre oral radiophonic publicity transmitted in the Alagoan radio. In this way, work understands Rhetoric as a discursive mechanism capable of verifying how persuasion takes place in the most diverse discourses. From this positioning, this study is methodologically linked to the qualitative perspective, since it emphasizes the data process and not the final product. The descriptiveinterpretative look of the qualitative approach allows the researcher to observe the data procedurally. Therefore, it is based on the theoretical references of Abreu (2009), Aristotle (2011), Ferreira (2015), Meyer (2007), Perelman \& Olbrechts-Tyteca (2014), Santos (2011, 2018), among others. The focus of the
\end{abstract}

\footnotetext{
* Mestrando pelo PPGLL/FALE/UFAL. ORCID: https://orcid.org/0000-0002-6333-5532. msrletras@gmail.com

** Doutora em Letras. Professora do PPGLL/FALE/UFAL e da UNEAL. ORCID: https://orcid.org/00000002-0455-6431. mfosal@gmail.com
} 
com destaque para a propaganda oral, que teve como suporte de veiculação uma emissora de rádio do agreste alagoano. Os resultados indicam que os argumentos quase lógicos com a junção dos lugares da argumentação foram utilizados de maneira decisiva pelos oradores, para o acontecimento do gênero propaganda oral radiofônica no rádio alagoano.

PALAVRAS-CHAVE: Argumentos. Lugares. Propaganda oral. analysis is the radiophonic space, especially the oral propaganda, which was broadcast by a radio station from the rural Alagoas. The results indicate that the almost logical arguments with the joining of the places of the argumentation were used decisively by the speakers, for the event of the radiophonic oral propaganda genre on the Alagoan radio.

KEYWORDS: Arguments. Places. Oral advertising.

\section{Considerações iniciais}

Este trabalho situa-se nos estudos da Nova Retórica e tem como principal objetivo estudar a presença dos argumentos quase lógicos e dos lugares da argumentação no gênero propaganda oral radiofônica, buscando responder à seguinte pergunta norteadora: por ser a propaganda oral radiofônica um gênero textual que está presente diariamente no rádio alagoano, de que maneira os oradores tentam persuadir?

Nesse sentido, a busca por responder à referida pergunta norteadora fundamenta o interesse por realizar esse trabalho. A propaganda analisada (pomada negra) foi colhida durante um programa de rádio de uma emissora do agreste alagoano. A propaganda é veiculada diariamente nas casas das pessoas, promovendo a divulgação do medicamento e, por consequência, persuadindo o auditório para que este adquira o produto que está à venda.

Outros trabalhos já foram realizados a partir do gênero propaganda oral radiofônica, a exemplo das autoras Figueiredo e Santos (2015) em que nomeiam o referido gênero de spot e destacam que é um gênero textual predominantemente da oralidade, que toma como suporte o rádio, configurando-se numa propaganda oral radiofônica. As autoras também se detêm ao rádio alagoano, mas a diferença deste trabalho para o delas acontece por este ser uma análise apenas dos argumentos quase 
lógicos e dos lugares da argumentação, a partir das contribuições da Nova Retórica; e aquele recorrer à junção da Análise da Conversação com a Nova Retórica, além de analisar uma série de categorias em várias propagandas orais.

Em um trabalho mais recente, Santos (2018) mostra a importância da propaganda oral radiofônica a partir dos estudos textuais e conversacionais. A autora afirma que o uso de elementos da referenciação promove a continuidade de sentidos do citado gênero oral. Além disso, a autora mostra a importância de estudar a propaganda oral à luz dos estudos textuais e conversacionais em que a fala e a escrita não se opõem, mas familiarizam-se promovendo o chamado contínuo tipológico.

A partir desses relevantes trabalhos já realizados, busca-se agora propiciar uma nova contribuição para a análise do gênero propaganda oral radiofônica do rádio alagoano, dessa vez com o objetivo de estudar a presença dos argumentos quase lógicos e dos lugares da argumentação no gênero em destaque. Nesse sentido, buscase entender como as categorias retóricas (argumentos quase lógicos e lugares da argumentação) são utilizadas por oradores para contribuir na eficácia comunicativa da propaganda oral e nas tentativas de persuadir o auditório (ouvintes) da citada rádio.

Este trabalho está dividido em algumas seções: a primeira refere-se aos estudos da Nova Retórica e a contribuição para este tipo de trabalho; a segunda trata dos argumentos quase lógicos postulados por Perelman e Olbrechts-Tyteca (2014); a terceira discorre acerca dos seis lugares da argumentação elencados por Abreu (2009); a quarta destaca os aspectos metodológicos e a análise propriamente dita; e, finalmente, a quinta diz respeito às considerações finais.

Nesse sentido, todos esses passos foram seguidos com o objetivo de observar como os argumentos quase lógicos e os lugares da argumentação são utilizados pelo orador, de forma decisiva, para o acontecimento do gênero propaganda oral radiofônica na rádio alagoana. 


\section{Acerca da Nova Retórica}

Este trabalho toma a Nova Retórica como uma faculdade do conhecimento capaz de fornecer subsídios suficientes e/ou satisfatórios para o estudo detalhado dos aspectos persuasivos da linguagem. Ao mencionar o termo faculdade, alude-se à definição dada por Aristóteles (2011). Segundo ele, “pode-se definir a retórica como a faculdade de observar, em cada caso, o que este encerra de propósito para criar a persuasão. Nenhuma outra arte possui tal função" (ARISTÓTELES, 2011, p. 44).

O estudo ancora-se na Nova Retórica, procurando investigar como acontecem as tentativas de persuasão no gênero propaganda oral radiofônica na rádio alagoana. Assim, infere-se que aquele que procura fazer uma análise retórica não deve se preocupar com o que é verdadeiro ou falso, mas sim com o que é verossímil. Nas palavras de Perelman e Olbrechs-Tyteca (2014, p. 1), “o campo da argumentação é o do verossímil, do plausível, do provável, na medida em que este último escapa às certezas do cálculo". A Retórica não julga se um fato é bom ou ruim, verdade ou mentira; contrariamente, ela fornece meios para observar o que cada caso comporta de efeito persuasivo.

A Retórica pode revelar como se faz a persuasão. Ora, compreende-se que a persuasão é criada em um dado evento comunicativo ao serem acionados recursos argumentativos. Além disso, são as técnicas argumentativas que criam os mais diversos efeitos persuasivos em um determinado auditório. Essas artimanhas estão ao dispor de oradores que lançam mão delas para realizar os mais diversos propósitos e/ou interesses comunicativos, sobretudo, aqueles que visam convencer e persuadir um determinado auditório.

Ao se falar das técnicas argumentativas, é imprescindível frisar que a Nova Retórica é definida de acordo com esse postulado. Nesse sentido, a Retórica "é o estudo das técnicas discursivas que permitem provocar ou aumentar a adesão dos espíritos às teses que se lhes apresentam ao assentimento" (PERELMAN; OLBRECHTS- 
TYTECA, 2014, p. 220). A definição acima mostra que, através da Retórica, é possível estudar os meios pelos quais acontecem as tentativas de persuasão, bem como as técnicas empreendidas pelos oradores.

Diante disso, a Retórica paira sobre o lugar do preferível daquilo que é melhor em uma dada situação em que o contraditório tem grande destaque. Desse modo, o discurso retórico não se limita apenas à razão, à racionalidade e à lógica dos fatos. Ele vai além, vai até causar efeitos emotivos no auditório, procurando transmitir as várias faces da linguagem, os vários sentidos que podem ser (re)construídos por determinado orador perante seu auditório social. Por isso que “estudar a persuasão é, essencialmente, estudar a comunicação do ponto de vista dos seus efeitos persuasivos" (SOUSA, 2001, p. 201).

O propósito da argumentação postulada pela Nova Retórica perelmaniana é fazer com que o auditório aceite as proposições apresentadas pelo orador. Nesse ínterim, há uma série de elementos que irão fazer com o que o auditório aceite ou não ser convencido e persuadido de fato pelo discurso do orador. Por exemplo, o uso de determinados argumentos é, sem dúvida alguma, um recurso para a estratégia persuasiva. Nesse sentido, entende-se que é por meio do discurso que se dá o convencimento e a persuasão, já que é por meio da linguagem que qualquer orador pode vir a ganhar a confiança do seu auditório.

O discurso postulado pela Nova Retórica é entendido como “toda produção verbal, escrita ou oral, constituída por uma frase ou por uma sequência de frases, que tenha começo e fim e apresente certa unidade de sentido" (REBOUL, 2004, p. XIV). A partir dessa conceituação, infere-se que é por meio do discurso oral e/ou escrito que se dá a persuasão.

A Retórica, desde Aristóteles, sempre foi concebida como um campo do conhecimento que tem no discurso sua base fundante, por isso que Reboul (2004, p. XIV) diz: “eis, pois, a definição que propomos: retórica é a arte de persuadir pelo 
discurso". Assim sendo, compreende-se que a retórica vem, a partir de recursos discursivos, fornecer meios para que um orador possa utilizá-los a seu favor a fim de obter a adesão dos que ouvem e/ou leem as proposições que lhes são apresentadas.

Entende-se que a Retórica dispõe de meios capazes de pôr em evidência as motivações que levaram um determinado orador utilizar, por exemplo, os argumentos quase lógicos em um dado discurso. Não se trata apenas de localizar o efeito e/ou a categoria retórica utilizada, mas também de, por meio da função hermenêutica, buscar entender o sentido de determinada utilização no discurso.

Desde a publicação do Tratado da Argumentação em 1958, a Retórica foi ganhando novas definições. Além das que já foram citadas anteriormente, tem-se a mais atual postulada por Meyer (2007, p. 25): “Assim sendo, a retórica é a negociação da diferença entre os indivíduos sobre uma questão dada". Percebe-se que a Retórica realmente ocupa o lugar da diferença, do contraditório, do conflito, da tensão, pois sem esses aspectos caracterizadores não haveria a necessidade de argumentar.

Meyer (2007) estudou a tríade persuasiva ethos, pathos e logos em construção. Desde Aristóteles, os meios de persuadir vinham sendo analisados de forma separada. O próprio estagirita se deteve em analisar o logos com maior ênfase; outros autores, como Reboul (2004) priorizaram o estudo do ethos; e outros, como Perelman e Olbrechts-Tyteca (2014), privilegiaram o pathos.

Diante do exposto, concorda-se com Meyer (2007), pois a ideia de estudar o ethos, pathos e logos de maneira conjunta favorece um maior entendimento dos discursos que visam à persuasão. Além disso, os meios de persuadir são como um tripé em que a existência de um está na do outro. Em relação a isso, aparece o comentário do próprio autor que ratifica essa ideia:

De tudo o que foi dito, decorre que o éthos, o páthos e o lógos devem ser postos em pé de igualdade, se não quisermos cair em uma concepção que exclua as dimensões constitutivas da relação retórica. $\mathrm{O}$ orador, o auditório e a linguagem são igualmente essenciais. Isso 
significa que o orador e o auditório negociam sua diferença, ou sua distância, se preferirmos, comunicando-a reciprocamente (MEYER, 2007, p. 25).

Desse ponto de vista, a tríade é inseparável, configurando-se numa implicação entre o eu com o ethos, o mundo com o logos e o outro com o pathos, conforme Meyer (2007). O primeiro é de caráter afetivo; o segundo, racional; e o terceiro é também afetivo. Há, nesse sentido, uma relação estreita entre ethos, pathos e logos. Diante disso, cada parte da tríade representa um meio que compõe o próprio discurso retórico. É importante trazer as considerações acerca de cada meio de persuadir.

O ethos "é uma excelência que não tem objeto próprio, mas se liga à pessoa, à imagem que o orador passa de si mesmo, e que o torna exemplar aos olhos do auditório, que então se dispõe a ouvi-lo e a segui-lo" (MEYER, 2007, p. 34-35). Em vista disso, o ethos diz respeito às virtudes, ao caráter do orador, à imagem que o orador constrói de si e que ela gera confiança diante de determinado auditório.

O pathos refere-se ao "conjunto de valores implícitos das respostas fora de questão, que alimentam as indagações que um indivíduo considera como pertinentes" (MEYER, 2007, p. 39). Entende-se, desse modo, que o pathos diz respeito às emoções, paixões, sentimentos que são despertados no auditório durante a argumentação. $\mathrm{O}$ orador recorre aos valores do auditório para torná-lo dócil, amável e, principalmente, adepto do discurso proferido.

O logos "deve poder expressar as perguntas e as respostas preservando sua diferença" (MEYER, 2007, p. 40). O logos diz respeito ao próprio discurso retórico em que o contraditório, a diferença, são elementos essenciais. É por meio do logos que qualquer orador lança mão de uma gama de argumentos para tentar persuadir o auditório.

Na propaganda oral radiofônica em estudo, o ethos é caracterizado pela própria marca e/ou empresa vendedora do produto pomada negra. O pathos é constituído por todos aqueles (auditório universal) que ouvem a propaganda oral (ouvintes da rádio). 
É importante dizer que o programa de rádio localiza-se no interior alagoano, o que prova ser uma escolha intencional a fim de se dirigir ao homem do campo. Finalmente, o logos caracteriza-se pelo encadeamento dos argumentos utilizados, objetivando fazer com que os ouvintes do programa de rádio comprem o referido produto que está sendo veiculado.

\section{Argumentação lógica no gênero propaganda oral radiofônica}

Segundo Perelman e Olbrechts-Tyteca, (2014, p. 220), a argumentação quase lógica é caracterizada por ser não formal e pelo esforço mental de que necessita sua redução ao formal. Assim, esse tipo de argumentação (quase lógica) "se apresentará de uma forma mais ou menos explícita. Ora o orador designará os raciocínios formais aos quais se refere prevalecendo-se do pensamento lógico, ora estes constituirão apenas uma trama subjacente" (PERELMAN; OLBRECHTS-TYTECA, 2014, p. 220).

Nesse sentido, infere-se que a argumentação quase lógica tem a função de tornar os argumentos, na medida do possível, incontestáveis, aludindo aos raciocínios formais e matemáticos que, aparentemente, não podem ser refutados e/ou contestados, visto que a natureza deles apresenta um caráter de exatidão e precisão. Desse modo, os argumentos quase lógicos ao se ancorarem nos postulados lógicos, geram confiança ao discurso proferido, no momento em que o orador argumenta perante um auditório particular e/ou universal.

Ainda acerca dos argumentos quase lógicos, é oportuno frisar que eles se apresentam como incontestáveis em uma argumentação. A precisão no momento da argumentação soa como se esses argumentos fossem exatos, visto que eles (os argumentos) são considerados mais fortes do que os de qualquer oponente. A certeza, a verdade ou a verossimilhança comprovada é o que testifica o uso da argumentação quase lógica. Santos (2011) atesta que os argumentos quase lógicos indicam ideias da contradição e de incompatibilidade, da identidade e da definição, da reciprocidade, da 
transitividade, da divisão, da inclusão e da comparação, entre outras. Algumas dessas ideias postuladas pela autora alagoana serão apreciadas neste trabalho.

Na concepção da Nova Retórica, entende-se que os argumentos quase lógicos são técnicas argumentativas por meio das quais o orador recorre para utilizar no discurso retórico. Abreu (2009, p. 47) ressalta que essas técnicas argumentativas são os fundamentos "que estabelecem a ligação entre as teses de adesão inicial e a tese principal. Essas técnicas compreendem dois grupos principais: os argumentos quase lógicos e os argumentos fundamentados na estrutura do real". Ambos os grupos (quase lógicos e fundados na estrutura do real) se baseiam naquilo que existe e que pode ser observado de acordo com a verdade ou com a verossimilhança. A realidade está posta e o uso dos argumentos se baseia nela.

Ainda assim, os argumentos quase lógicos se apresentam explicitamente e têm a sua força persuasiva "na proximidade (semelhança) com argumentos formais: o orador designará os raciocínios formais aos quais se refere, prevalecendo-se do prestígio do pensamento lógico, ora estes constituirão uma trama subjacente" (FERREIRA, 2015, p. 149-150). Pode-se, desse modo, inferir que esses argumentos (quase lógicos) não são necessariamente o que se dizem ser, por isso, a ideia de incompletude, isto é, eles são quase lógicos.

Dentro desse mesmo contexto, é o esquema formal que impera na argumentação quase lógica. É importante dizer que tais argumentos (quase lógicos) possuem uma aparência lógica além de que eles "não fazem apelo à experiência porque procuram demonstrar. Como, porém, não são lógicos, permitem a refutação, ou seja, que o adversário mostre que não são puramente lógicos"' (FERREIRA, 2015, p. 150). A ideia indica a não concretude, por isso a possibilidade de refutação, mesmo que eles estejam amparados em fórmulas lógicas.

Reboul (2004, p. 168) destaca que os argumentos quase lógicos não fazem apelo à experiência, ao vivido comumente, ao afirmar: "ao contrário dos princípios lógicos 
da demonstração, podem ser refutados demonstrando-se que não são 'puramente lógicos'". Nesse sentido, os argumentos quase lógicos não possuem um valor conclusivo, embora se apoiem em propriedades de estrutura lógico-formais. A possibilidade de refutação existe e é possível. Assim, a sustentação dos argumentos não é puramente lógica, pois se fosse, não poderia ser refutada.

Dentre todos os argumentos quase lógicos, este trabalho se detém apenas nos argumentos a inclusão das partes no todo, a divisão do todo em suas partes, a definição e o ridículo. A escolha por esses argumentos se deu pelo fato de o gênero propaganda oral radiofônica ter sido veiculado na rádio alagoana e o orador ter a recorrido a ela a fim de conseguir a confiança do auditório, para que este adquira o medicamento (pomada negra), que está sendo vendido pelo anunciante. Por isso, é de suma importância discorrer sobre cada um desses argumentos quase lógicos, mostrando como eles são conceituados pelos estudos da Nova Retórica.

$\mathrm{O}$ argumento quase lógico a inclusão do todo em suas partes diz respeito à importância que o todo possui em relação às partes que o constitui como em uma espécie de dependência destas. "Os argumentos derivados da inclusão da parte no todo permitem formular o problema de suas relações com os lugares da quantidade" (PERELMAN; OLBRECHTS-TYTECA, 2014, p. 264). Dessa maneira, o todo engloba as partes e configura-se hierarquicamente mais importante.

O argumento quase lógico a divisão do todo em suas partes indica a fragmentação do todo e ao mesmo tempo mostra a importância de suas partes para a sua constituição, numa relação de interdependência entre ambas (partes e todo). Diante disso, "para a utilização eficaz do argumento por divisão, a enumeração das partes tem de ser exaustiva"' (PERELMAN; OLBRECHTS-TYTECA, 2014, p. 266).

O argumento quase lógico da definição é classificado como o uso de uma identificação entre o que é definido e o que define. "O procedimento mais característico de identificação completa consiste no uso das definições" (PERELMAN; 
OLBRECHTS-TYTECA, 2014, p. 238). A definição seja ela de qualquer tipo (normativa, descritiva, condensada e/ou complexa) é um argumento quase lógico.

$\mathrm{O}$ argumento quase lógico do ridículo refere-se a tudo aquilo que promove a tensão, o conflito e que provoca o riso. “O ridículo é aquilo que merece ser sancionado pelo riso [...] uma afirmação é ridícula quando entra em conflito, sem justificação, com uma opinião aceita" (PERELMAN; OLBRECHTS-TYTECA, 2014, p. 233). Por meio desse argumento, qualquer orador pode condenar e/ou ironizar uma dada situação.

Finalmente, todos esses (e outros) argumentos quase lógicos que foram teorizados estão a serviço de oradores que buscam convencer e persuadir determinados auditórios particulares e/ou universais. Por auditório, entende-se: “o conjunto daqueles que o orador quer influenciar com sua argumentação" (PERELMAN; OLBRECHTS-TYTECA, 2014, p. 233). Além disso, “cada orador pensa, de uma forma mais ou menos consciente, naqueles que procura persuadir e que constituem o auditório ao qual se dirigem seus discursos" (PERELMAN; OLBRECTHS-TYTECA, 2014, p. 22).

O uso eficiente dos argumentos quase lógicos pode resultar numa possível adesão por parte daqueles que ouvem a argumentação quase lógica. Diante disso, presume-se que no gênero propaganda oral radiofônica, a utilização desses (e outros) argumentos não acontece de maneira inconsciente, mas com uma intencionalidade ${ }^{1}$ previamente definida: persuadir o auditório, configurado por todos aqueles que ouvem a propaganda oral no rádio alagoano.

\section{Considerações acerca dos lugares da argumentação}

Santos (2011, p. 51) aponta os lugares da argumentação como uma categoria responsável pela classificação dos argumentos, além promover os valores em que o

\footnotetext{
1 Termo provindo dos Estudos Textuais e Discursivos, cujo significado está relacionado ao objetivo do produtor de um texto e/ou discurso ao falar, escrever.
} 
auditório está ancorado. A autora frisa que os lugares dão ao orador recursos para que consiga estabelecer acordos com o auditório. No mesmo entendimento, Abreu (2009, p. 85) afirma que os lugares da argumentação são premissas que servem para reforçar “a adesão a determinados valores. O nome lugares era utilizado pelos gregos, para denominar locais virtuais facilmente acessíveis, onde o orador pudesse ter argumentos à disposição, em momento de necessidade".

Nesse sentido, infere-se que os lugares da argumentação estão a serviço do orador para que possa, no momento da argumentação, buscar os argumentos que deseja para tentar convencer e persuadir um determinado auditório. Assim, compreende-se que os lugares da argumentação configuram-se em grandes celeiros de argumentos que são "utilizados para estabelecer acordos com o auditório. O objetivo é indicar premissas de ordem ampla e geral, usadas para assegurar a adesão a determinados valores e, assim, re-hierarquizar as crenças do auditório" (FERREIRA, 2015, p. 69).

Seguindo Abreu (2009, p. 85), é possível classificar os lugares da argumentação em seis tipos: lugar de quantidade; lugar de qualidade; lugar de ordem; lugar de essência; lugar de pessoa; e lugar do existente. Por meio da utilização desses lugares retóricos, qualquer orador pode explorar a hierarquia de valores de qualquer auditório, procurando aumentar a intensidade da adesão. Assim, esses lugares, conforme Ferreira (2015, p. 70), estão à disposição do orador para a criação dos argumentos e, por consequência, para as tentativas de persuadir determinado auditório.

O lugar de quantidade caracteriza-se pela utilização de formas numéricas. É neste lugar onde qualquer coisa vale mais que outra em função de razões quantitativas. De acordo com o lugar de quantidade, "um bem que serve a um número muito grande de pessoas tem mais valor do que um bem que serve apenas a um pequeno grupo. Um 
bem mais durável é superior a um bem menos durável e assim por diante" (ABREU, 2009, p. 85-86).

O lugar de qualidade mostra que uma coisa é melhor do que outra porque possui mais qualidades ao ser comparada com seus semelhantes. Assim, “o lugar de qualidade se contrapõe ao lugar de quantidade, pois contesta a virtude do número. Valoriza o único, o raro" (ABREU, 2009, p. 88). Nesse sentido, aquilo que é único e raro sobrepõe tudo aquilo que é corriqueiro, comum.

O lugar de ordem é o lugar que apresenta a sequência de fatos, isto é, primeiro há uma causa e, em seguida, um efeito produzido por ela. No entanto é preciso entender que o anterior é mais importante do que o posterior, já que aquele veio primeiro do que este. Diante disso, "o lugar de ordem afirma a superioridade do anterior sobre o posterior, das causas sobre os efeitos, dos princípios sobre as finalidades etc." (ABREU, 2009, p. 90).

O lugar de essência caracteriza-se por tudo aquilo que emana das pessoas que são consideradas as que melhor representam a classe à qual são pertencentes. São consideradas modelos de uma determinada essência. Por isso, tem-se que “o lugar de essência valoriza indivíduos como representantes bem caracterizados de uma essência"' (ABREU, 2009, p. 93-94).

O lugar de pessoa diz respeito à valorização do ato realizado por uma pessoa ou até mesmo o cuidado pelo ser humano, ou seja, esse lugar retórico utiliza-se da iniciativa de indicar melhores condições voltadas ao bem-estar do homem. Por isso, "o lugar de pessoa afirma a superioridade daquilo que está ligado às pessoas. Primeiro as pessoas, depois as coisas! é o slogan que materializa esse lugar"' (ABREU, 2009, p. 94-95).

O lugar do existente fundamenta-se na superioridade do que é real sobre aquilo que pode vir acontecer. É partir desse lugar retórico que o orador busca falar daquilo que é vivido, experienciado no aqui e no agora. Nesse sentido, "o lugar do existente 
dá preferência àquilo que já existe, em detrimento daquilo que não existe" (ABREU, 2009, p. 95-96).

Portanto, todos esses lugares retóricos e, ao mesmo tempo da argumentação, encontram-se à disposição e são utilizados por qualquer orador para construir os argumentos e, desse modo, aumentar a intensidade da adesão perante um determinado auditório. É no momento de necessidade argumentativa que os oradores recorrem a esse celeiro que agrupa os mais diversos argumentos.

\section{Análise retórica da propaganda oral radiofônica}

Para estudar o gênero propaganda oral radiofônica, foi necessário colher o material de análise durante um programa de rádio de uma determinada emissora do agreste alagoano. Ao conseguir o corpus de análise, ocorreram as transcrições, visto que se trata de um gênero da modalidade de língua oral. As transcrições foram realizadas de acordo com os estudos de Marcuschi (2003), Preti (1999), Santos, Dickson e Morais (2014), entre outros.

O trabalho segue os caminhos da pesquisa qualitativa com um olhar descritivointerpretativista (FLICK, 2009), pois dá ênfase ao processo pelo qual ocorre o fenômeno analisado. No dizer de Oliveira (2010, p. 24), “o processo interpretativo passa por três estágios: o descrever, o dar sentido ao dado e argumentar". Assim, a interpretação dos dados, a partir das categorias retóricas previamente elencadas, mostra como acontece o gênero propaganda oral de linha radiofônica.

Flick (2009) diz que os aspectos essenciais da pesquisa qualitativa consistem na escolha adequada de métodos e de teorias convenientes; no reconhecimento e na análise de diferentes perspectivas; nas reflexões dos pesquisadores a respeito de suas pesquisas como parte do processo de produção de conhecimento; e na variedade de abordagens e de métodos. À luz dessa abordagem, foi possível verificar como o gênero em destaque está organizado pelas artimanhas retóricas. 


\section{Amostragem e análise retórica}

O produto em destaque é a pomada negra, que serve para tratar das dores do corpo, além de ser útil para uma série de problemas decorrentes do esforço físico, principalmente daqueles originários dos trabalhos rurais. A principal intenção da propaganda é a venda do medicamento. É possível ver estes aspectos no texto a seguir:

L1: e:::cumpade eu não tô bom não viu é dor no pescoço nas junta nas costa cruz credo...

L2: use a pomada NEGRA cumpade...a pomada negra é composta por óleo de pinheiro bravo óleo de copaíba que tem ação anti-inflamatória e de relaxante muscular...a pomada negra alivia tensões musculares dor nas articulações artrite artrose lesões contusões e reumatismo óia pomada negra alivia também as dores chikungunya dengue zikavírus câimbras e mal jeito no pescoço cumpade L1: e::cumpade só docê falar já começou a miorá (risos)

L3: pomada negra a venda somente nas farmácias e casas de produtos naturais... Fonte: corpus da pesquisa (2019).

A propaganda oral radiofônica inicia com o diálogo entre dois camponeses. Um deles está reclamando de dores pelo corpo, como pode ser visto em: “e:::cumpade eu não tô bom não viu é dor no pescoço nas junta nas costa cruz credo...". Verifica-se que o orador (L1) recorre ao argumento (quase lógico) da inclusão das partes no todo para efetivar o discurso. Nesse sentido, o todo se caracteriza pelo corpo humano; as partes, por sua vez, correspondem ao pescoço, às juntas, às costas. Talvez, as dores relatadas pelo primeiro orador (L1) sejam fruto de um dia inteiro de labuta na roça. Assim, o modo como o discurso foi colocado é estratégico e persuasivo porque desperta, no auditório, sentimentos, paixões (pathos), as quais propiciam a possibilidade de o auditório adquirir o medicamento pomada negra, caso esteja com os mesmos sintomas descritos pelo orador (L1).

Em seguida, para que o orador (L1) melhore das dores que vinha sentindo pelo corpo, o orador (L2) indica uma possibilidade para a revitalização do corpo: "use a pomada NEGRA cumpade...". Ao utilizar essa expressão imperativa, o orador (L2) 
recorre ao lugar retórico da qualidade, pois dentre outras possibilidades de medicamentos, ele ordena que o compadre use apenas a pomada negra. Assim, inferese que tal pomada é algo único, raro, a melhor entre as outras pomadas, para resolver as mazelas que o orador (L1) adquiriu durante as lamúrias diárias. Por a rádio veiculadora dessa propaganda ser do interior de Alagoas, acredita-se que, possivelmente, trata-se de direcionar o uso do medicamento para os trabalhadores rurais e todos aqueles que se interessarem pela pomada negra.

Posteriormente, o orador (L2) começa a explicar a composição do medicamento pomada negra. Ele afirma: “...a pomada negra é composta por óleo de pinheiro bravo óleo de copaíba que tem ação anti-inflamatória e de relaxante muscular...". É possível notar que o orador (L2) utilizou-se do argumento (quase lógico) a divisão do todo em suas partes. Desse modo, o todo é constituído pela própria pomada negra e as partes são o óleo de pinheiro, de copaíba, o relaxante muscular etc. Mais uma vez, nota-se que a intenção do orador é mostrar a importância do medicamento, mas também, sobretudo, persuadir o auditório para que possa comprar e usar o medicamento pomada negra.

O orador (L2) continua argumentando acerca da importância do medicamento e após mostrar as partes que constituem a pomada negra, ele agora passa a evidenciar a funcionalidade do produto: "a pomada negra alivia tensões musculares dor nas articulações artrite artrose lesões contusões e reumatismo óia pomada negra alivia também as dores chikungunya dengue zikavírus câimbras e mal jeito no pescoço cumpade". Ao mostrar os efeitos produzidos por aqueles que consomem o produto pomada negra, o orador (L2) recorre ao argumento (quase lógico) da definição porque mostra para o auditório a função do medicamento, além de mostrar as eficácias dele. O argumento da definição é utilizado visando persuadir o auditório.

O lugar retórico da ordem também é destacado no discurso do orador (L2). Compreende-se que o orador (L2) coloca as eficácias do produto em ordem, pois 
primeiro, a pomada negra "alivia as tensões musculares", depois "as dores nas articulações", em seguida atua contra o "reumatismo" e contribui até com a melhoria das dores provocadas pela "dengue". Observa-se que os fatos ocasionados pelo uso da pomada negra são colocados em ordem sequencial e culminam na saúde do homem. Diante disso, o anterior (todas as melhorias para alcançar a saúde) é mais importante e crucial do que o posterior (a melhoria em si), pois se não houvesse o primeiro, o segundo obviamente não existiria. Portanto, primeiro é necessário utilizar a pomada negra e somente depois será possível desfrutar das eficácias do medicamento.

Além do lugar retórico da ordem, é possível perceber também a presença do lugar retórico de pessoa, pois o orador (L2) mostra o cuidado pela saúde do homem, visto que a pomada negra: “alivia tensões musculares dor nas articulações artrite artrose lesões contusões e reumatismo...". Verifica-se que o principal objetivo do medicamento é cuidar da saúde, do bem-estar da pessoa humana, tentando evitar que possíveis doenças danifiquem o corpo humano, neste caso, o dos trabalhadores camponeses. Por isso, o lugar retórico é evocado, já que ele testifica que a pomada negra visa ao melhor para a saúde das pessoas.

O lugar retórico de essência também está presente na propaganda oral em destaque, mas de forma implícita. Compreende-se que os próprios camponeses representam melhor a classe dos trabalhadores rurais. Ora, há várias características de trabalhadores, mas os camponeses ocupam socialmente modelos que encarnam uma função específica: produzir alimentos para a sua própria existência, bem como de toda a população. Assim, os camponeses representam a essência daquilo que seria um trabalhador rural dedicado a cooperar com um bem comum para todos: a produção de alimentos.

Outro lugar retórico que foi bastante explorado pelo orador (L2) foi o da quantidade. O orador (L2) aponta uma série de elementos que compõem a pomada negra: “a pomada negra é composta por óleo de pinheiro bravo óleo de copaíba que 
tem ação anti-inflamatória e de relaxante muscular...". Percebe-se um grande quantitativo de elementos que constituem o referido medicamento. Além desses, existem aqueles que são fruto do uso da pomada: "alivia tensões musculares dor nas articulações artrite artrose lesões contusões e reumatismo óia pomada negra alivia também as dores chikungunya dengue zikavírus câimbras e mal jeito no pescoço cumpade". Com um quantitativo de elementos eficazes, as razões numéricas tornamse persuasivas.

Perto de finalizar a propaganda oral, o orador (L1) retoma novamente o discurso e enuncia: “e::cumpade só docê falar já começou a miorá (risos)”. Depois de o orador (L2) mostrar a importância e a constituição do produto pomada negra, o orador (L1) utiliza-se do argumento (quase lógico) do ridículo para causar um efeito persuasivo no auditório. Além disso, sanciona o riso porque o medicamento não tem esse poder de curar alguma enfermidade por apenas falar acerca do produto. Outro ponto importante diz respeito ao fato de apenas falar sobre o produto por ser tão persuasivo, já acontece uma melhoria na saúde do orador (L1), imagine se ele tivesse usado a pomada negra. A tentativa de persuadir acontece por meio dos recursos retóricos que estão acoplados aos discursos dos oradores e são utilizados como artimanhas persuasivas no gênero propaganda oral radiofônica.

O lugar do existente foi contemplado na propaganda oral, pois no primeiro momento o orador (L1) afirma: “eu não tô bom não viu é dor no pescoço nas junta nas costa cruz credo...". Assim, as dores realmente existem e afligem um dos oradores. No entanto o que possivelmente ainda não existe na casa do orador (L1) é a própria pomada negra. Ao saber das dores do orador (L1), o orador (L2) não perde tempo e indica o medicamento a ser adquirido para curar as enfermidades. Ele é categórico: "use a pomada NEGRA cumpade...". Observa-se que aquilo que existe (as dores no corpo) é superior ao que não existe ainda (a pomada negra). 
A propaganda oral é finalizada com um terceiro orador (L3) que surge apenas para concluir a argumentação. Ele não se expressa como camponês, mas sim como um possível responsável direto pelo produto. Ele diz: "pomada negra a venda somente nas farmácias e casas de produtos naturais...". Diante disso, infere-se que a pomada negra é tão especial que não é vendida em qualquer lugar, mas apenas em farmácias e casas de produtos naturais.

Além disso, o que desperta curiosidade é que não foram os camponeses que finalizaram a propaganda, mas um terceiro orador. Este não tem a linguagem popular, coloquial, natural dos homens da roça, mas sim uma linguagem culta. Acredita-se que agora realmente aparece o ethos da empresa que utilizou os camponeses apenas para persuadir o auditório.

Em vista disso, o orador (L3) encerra a propaganda, recorrendo, mais uma vez, ao lugar da qualidade, evidenciando que a pomada negra é o melhor entre os demais produtos. Como foi demonstrado, não é qualquer medicamento, mas é a pomada negra.

Os argumentos quase lógicos (a inclusão das partes no todo; a divisão do todo em suas partes; a definição; o ridículo), que foram utilizados pelo orador (radialista) no discurso evidenciam que o gênero propaganda oral radiofônica é organizado e efetivado a partir desses tipos de argumentos. Todos eles foram encadeados de maneira estratégica, procurando granjear a confiança do auditório.

Concomitante a isso, surgiram também os lugares da argumentação (lugar de quantidade, lugar de qualidade, lugar de ordem, lugar de pessoa, lugar de essência e lugar do existente), que foram utilizados constantemente pelos oradores da propaganda oral radiofônica.

Portanto, essas categorias retóricas (argumentos quase lógicos e lugares da argumentação) contribuem para o acontecimento do gênero propaganda oral radiofônica veiculada na rádio alagoana. 


\section{Considerações finais}

Este trabalho objetivou realizar uma análise acerca dos argumentos quase lógicos e dos lugares da argumentação no gênero propaganda oral radiofônica do rádio alagoano. Por meio da análise retórica, foi possível perceber que as duas categorias analisadas (argumentos quase lógicos e os lugares da argumentação) foram utilizadas pelos oradores para organizar e fazer com que o citado gênero aconteça de maneira organizada.

No que diz respeito à utilização dos argumentos quase lógicos, verificou-se que a sua escolha pelo orador (radialista), como: a inclusão das partes no todo, a divisão do todo em suas partes, a definição e o ridículo, não se deu por acaso. Todos esses argumentos têm um objetivo específico: persuadir o auditório, constituído por todos os ouvintes do programa de rádio, para que todos possam comprar a pomada negra.

No tocante aos lugares da argumentação, foi possível identificar o lugar da quantidade, da qualidade, da ordem, da essência, da pessoa e do existente. Todos os lugares retóricos apontados por Abreu (2009) foram contemplados na propaganda analisada. A utilização desses lugares da argumentação com a junção dos argumentos quase lógicos evidencia o sentido persuasivo presente no referido gênero textual.

Por meio do uso das categorias retóricas estudadas, a propaganda oral radiofônica conseguiu promover o medicamento e mostrar para o auditório as possíveis eficácias adquiridas quando ao uso da pomada negra. O objetivo principal da propaganda em destaque é fazer com que o auditório (ouvintes do programa da rádio) adquira o produto que está à venda.

A propaganda é veiculada diariamente na rádio interiorana e para um público interiorano com tentativas de persuadir o auditório. Ora, se o medicamento não estivesse sendo vendido, talvez a propaganda deixasse de ser veiculada na rádio, já que há pagamentos para que tal veiculação aconteça. O possível sucesso de venda está 
intrínseco à utilização dos recursos retóricos ora analisados, pois sem eles, provavelmente, a propaganda não teria êxito.

Por fim, este trabalho procurou contribuir com o estudo retórico da propaganda oral radiofônica da rádio alagoana. Esse gênero apresenta categorias retóricas como os argumentos quase lógicos e os lugares da argumentação, os quais foram utilizados pelo orador decisivamente para o acontecimento e a organização do referido gênero de linha radiofônica. Assim, pode-se afirmar que o gênero propaganda oral radiofônica é retórico e visa à persuasão do auditório.

\section{Referências}

ABREU, A. S. A arte de argumentar: gerenciando razão e emoção. 13. ed. Cotia: Ateliê Editorial, 2009.

ARISTÓTELES. Retórica. São Paulo: Edipro, 2011.

FERREIRA, L. A. Leitura e persuasão: princípios de análise retórica. São Paulo: Contexto, 2015.

FIGUEIREDO, M. F.; SANTOS, M. F. O. Do rádio para a sala de aula: uma análise retórico-conversacional do gênero spot. Filol. Linguíst. Port., São Paulo, v. 17, n. 1, p. 205-225, jan./jun, 2015. DOI https://doi.org/10.11606/issn.2176-9419.v17i1p205-225.

FLICK, U. Introdução à pesquisa qualitativa. 3. ed. Porto Alegre: Artmed, 2009.

MARCUSCHI, L. A. Análise da Conversação. 5. ed. São Paulo: Editora Ática, 2003.

MEYER, M. A retórica. São Paulo: Ática, 2007.

OLIVEIRA, A. A. Observação e entrevista em pesquisa qualitativa. Revista FACEVV, Vila Velha, n. 4, p. 22-27, 2010.

PERELMAN, C.; OLBRECHTS-TYTECA, L. Tratado da argumentação: a nova retórica. 3. ed. São Paulo: Martins Fontes, 2014. 
PRETI, D. (org.) Análise de textos orais. 4. ed. São Paulo: Humanitas Publicações FFLCH/USP, 1999.

REBOUL, O. Introdução à retórica. São Paulo: Martins Fontes, 2004.

SANTOS, M. F. O. As marcas retórico-críticas no gênero editorial. Maceió: Edufal, 2011.

SANTOS, M. F. O. O gênero spot à luz dos estudos da argumentação e da referenciação. In: SANTOS, M. F. O; ROCHA, M. S. (org.). Teceres diferentes em gêneros orais e escritos. Arapiraca: EDUNEAL, 2018.

SANTOS, M. F. O; DIKSON, D; MORAIS, E. P. Interfaces com a análise da conversação: olhares diversos em teorias imbricadas. Maceió, AL: EDUFAL, 2014.

SOUSA, A. A persuasão. Covilhã: Universidade da Beira Interior, 2001. 